\title{
MAGNETIC PROPERTIES STUDY OF TEXTURED
} CO-Ni DEPOSITS

\section{N. FENINECHE, O. EL KEDIM and C. CODDET LERMPS}

UTC Sevenans 90010 BELFORT CEDEX

\section{SUMMARY:}

The effect of the elaboration parameters on the structural state of Co-Ni deposits and particularly the texture and its relationships to the magnetic properties have been studied. Experimental conditions were selected in a manner that the chemical composition of the deposits remained almost unchanged $(80-82 \% \mathrm{Co}, 18-20 \% \mathrm{Ni})$. Bright and smooth deposits characterised by $[11 \overline{2} 0]$ or $[11 \overline{2} 0]+[10 \overline{10}]$ texture axis with interesting magnetic properties were thus obtained.

\section{INTRODUCTION}

The electrodeposition of alloys has gained importance in the recent years for its practical applicability in modern industrial technology. Recent efforts have been particulary directed towards the preparation of magnetic alloys such as $\mathrm{Co}-\mathrm{Ni}, \mathrm{Fe}-\mathrm{Co}$ and $\mathrm{Ni}-\mathrm{Fe}$; these alloys are of great interest in the sophisticated electronics industries related to rocketry, computers, space technology , etc...

The purpose of this work was to try and relate the microstructure of Co-Ni alloys and especially their texture and their magnetic properties to the plating conditions. Indeed, the electroplating technique remains still inegaled because it generally allows the obtention of thick and textured deposits, properties which are of great importance. 
In this work, electroplating was performed from a solution based on cobalt and nickel chlorides with additives on a copper substrate. Experimental details will be found in previous papers $(1,2)$.

\section{EXPERIMENTAL RESULTS :}

In order to determine the structural state effects on the magnetic characteristics of the deposits, three parameters were considered : the current density, the $\mathrm{pH}$ and the bath temperature. The diffractometric analysis of the deposits revealed in all cases a solid solution at a steady state with an hcp structure. The solid solution stability was confirmed by a tempering treatment at $500{ }^{\circ} \mathrm{C}$.

Detailed results about the effect of the electrodeposition parameters on the microstructure of the alloys were already described elsewhere (1-2). The diagram reported in (fig.1) summarizes the obtention's domains of the different texture's axes as a function of the current density and of the solution's $\mathrm{pH}$.

The stability domains are separated by border lines the precision of which was estimated to be $\pm 3 \mathrm{~mA} / \mathrm{cm}^{2}$; the limits between some domains ([11 $\overline{2} 0],[21 \overline{3} 0]+[11 \overline{2} 0]$ and $[10 \overline{1} 0])$ have been represented by discontinuous lines because of the difficulties to control the $\mathrm{pH}$ for its lower values. Thus, for a $\mathrm{pH}$ and a temperature corresponding to usual conditions of the solution ( $\mathrm{pH}=3,5$ and $\mathrm{T}=25^{\circ} \mathrm{C}$ ) and for increasing values of the current density, the following texture's axes sequence was obtained: $[11 \overline{2} 0],[1 \overline{12} 0]+[10 \overline{1} 0],[21 \overline{3} 0]+[11 \overline{2} 0],[10 \overline{1} 0]$. The deposits obtained at low current densities are generally caracterised by $[1 \overline{1} \overline{2} 0]$ texture's axis, while the $[21 \overline{3} 0]$ texture's axis is often met at low $\mathrm{pH}$. However, the results obtained, especially those involving texture's axes, can hardly be 


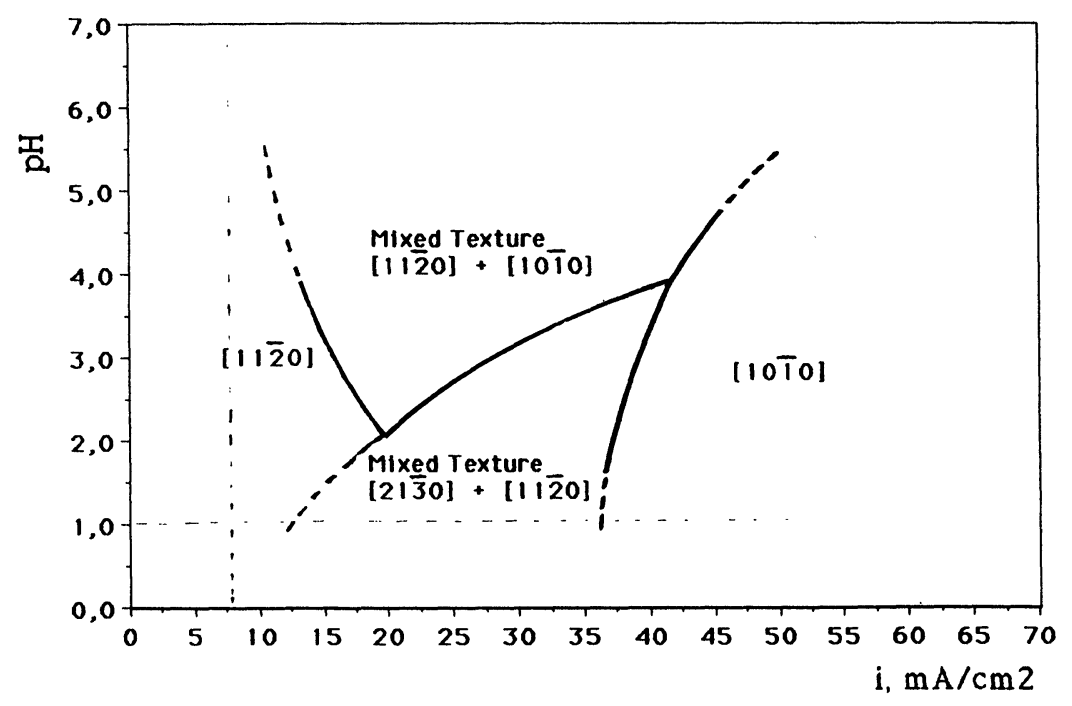

Fig. 1: Stability areas of the different textures at $\mathrm{T}=23^{\circ} \mathrm{C}$

(the hcp structure remains unchanged, except a slight variation of lattice parameters).

compared with those of the litterature. For example, it is possible to consider, in agreement with Reddy's theory (3) that hydrogen adsorption can be responsible for the formation of the $[21 \overline{3} 0]$ texture axis but the interpretation of the role of the different electrolytic parameters (current density, $\mathrm{pH}$ and temperature etc...) doesn't coincide with those observed. On a same manner, the Pangarov's theory (4) predicts the following texture's axes sequence: [00 $\overline{0} 1],[10 \overline{10}],[11 \overline{20}],[10 \overline{10}]$ and [11 22 ] which was not found in our diagrams at any bath $\mathrm{pH}$.

In a first time, the evolution of the magnetic characteristics, particularly, the coercivity Hc, was followed as a function of the deposit thickness $t$. It was observed that $\mathrm{Hc}$ is a decreasing function of the thickness $t$ according well with the general relation given in the literature (5):

$\mathrm{Hc}=\mathrm{A} \cdot \mathrm{t}^{-\mathrm{n}}$ where $\mathrm{A}$ is a constant and $0<\mathrm{n}<1$ 


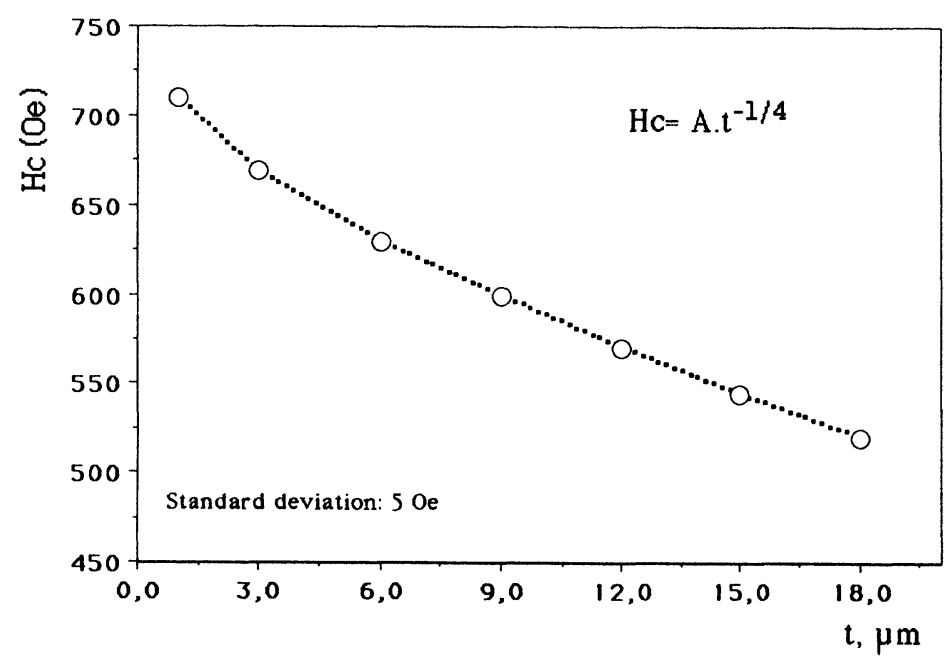

Fig.2: Dependance of the coercivity $\mathrm{Hc}$ on the deposit thickness $\mathrm{t}\left(\mathrm{i}=2.0 \mathrm{~A} / \mathrm{dm} 2 ; \mathrm{pH}=3.5 ; \mathrm{T}=23^{\circ} \mathrm{C}\right)$.

In the present case of the Co-Ni alloys (fig.2), $\mathrm{n}=0,25$. Consequently the coercivity evolution as a function of the deposit thickness seems to be related not to the composition distribution but to the structural state evolution, particularly the grain size and the texture's axes.

The figure 3 shows the evolution of the coercivity and of the squareness ratio $(\mathrm{Mr} / \mathrm{Ms})$ as a function of the current density. It was noted that an increase of the current density parameter contributes considerably in a sharp decrease of the magnetic properties of the alloys.

This change in the structural state affects not only the texture's axes, but also the granular structure; therefore the evolution of these characteristics was examined with the variation of the bath's $\mathrm{pH}$ for a determined current density value (fig.4). It was observed in this case that the lamellar structure obtained at low $\mathrm{pH}$, similar to that obtained at low 


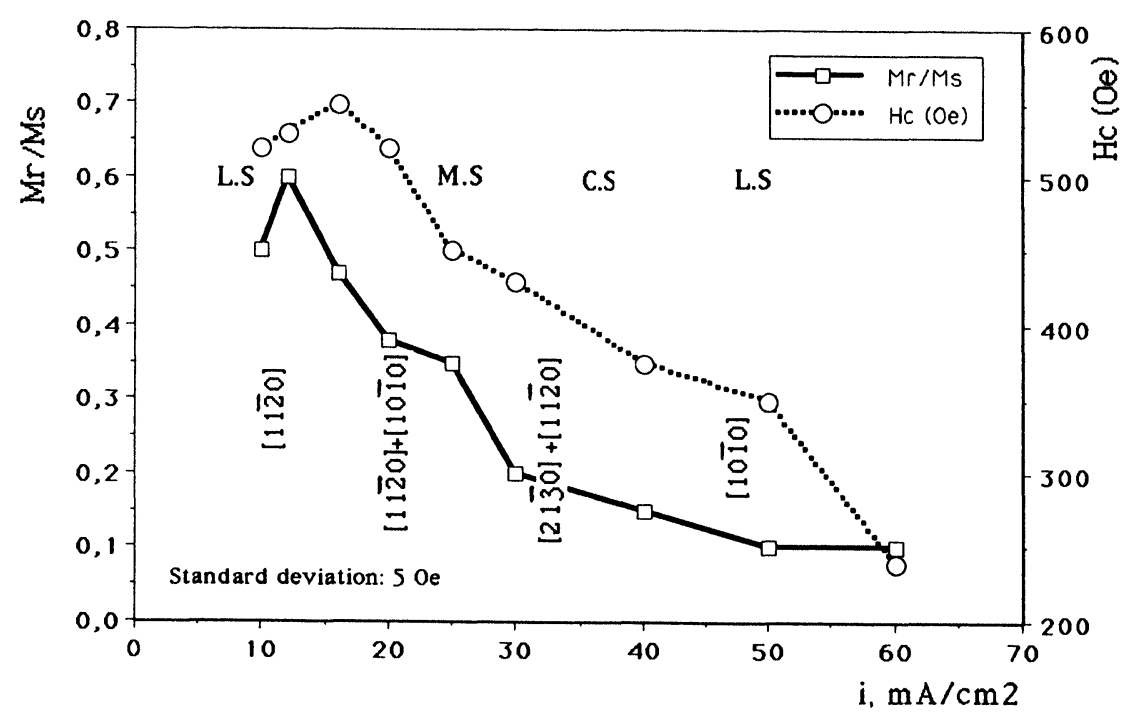

Fig.3: Variation of the coercivity, Hc, and of the squareness ratio, $\mathrm{Mr} / \mathrm{Ms}$, with the current density $\left(\mathrm{pH}=3,5 ; \mathrm{T}=23^{\circ} \mathrm{C}\right)$.

current densities, exhibit low magnetic characteristics. Consequently, the change in the magnetic properties is probably directly related to an evolution of texture's axes, and not to the granular structure; thus, the $[11 \overline{2} 0]+[10 \overline{10}]$ texture's axes correspond especially to interesting magnetic properties.

\section{III-CONCLUSION:}

From the present results, it seems still difficult to forsee with certitude the effect of each structural parameters on the magnetic properties. Nevertheless, for a given composition of the alloy it was observed that:

- a deposit thickness between 1 and $5 \mu \mathrm{m}$ is suitable from a magnetic point of view.

- a columnar or a mixed structure with $[11 \overline{2} 0]+[10 \overline{1} 0]$ or a [11 20$]$ texture axes are expected to improve the magnetic properties of the deposit. 


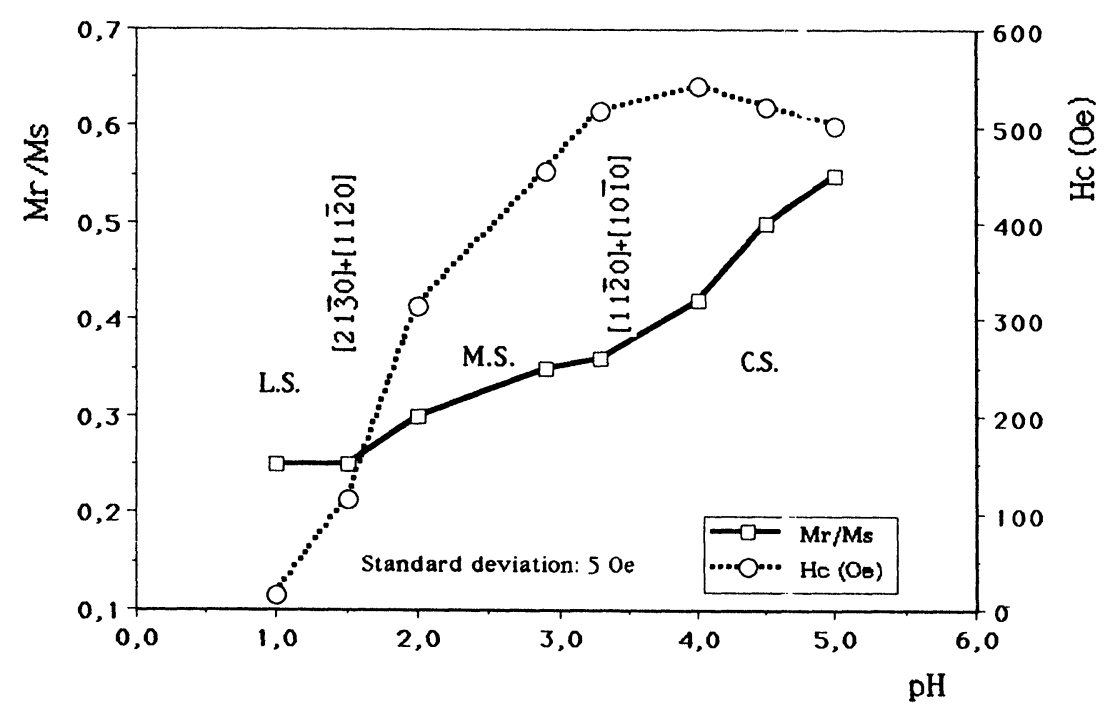

Fig. 4 : Effect of the pH on the coercivity, Hc, and the squareness ratio, $\mathrm{Mr} / \mathrm{Ms}\left(\mathrm{i}=2.0 \mathrm{~A} / \mathrm{dm} 2 ; \mathrm{T}=23^{\circ} \mathrm{C}\right)$.

\section{REFERENCES :}

1 - N.E. Fenineche, Thesis. Université de CompiègneSevenans. 1990.

2- N.E. Fenineche, C. Coddet and A. Saida, Surface and Coatings Technology, 41(1990)75-81.

3- A.K.N. Reddy and S.R. Rajakopalan, J. Electroanal. Chem, 6(1963)141.

4- N.A. Pangarov, J. Electroanal. Chem, 9(1965)70.

5- S. N. Srimathi, S. M. Mayanna and B. S. Sheshadri, Surf. Technol, 16(1982)299.

AKNOWLEDGMENTS : The authors wish to express their thanks to Mrs. A.M. CHAZE CEMEF, Sophia Antipolis and Mr. J.M. DESVIGNES CNRS, Meudon for their contribution to experimental measurements respectively texture analysis and magnetic properties. 